\title{
On the basic-applied continuum in ecology and evolution and a call to action-perspectives of an early career researcher in academia
}

\author{
Steven J. Cooke \\ Steven J. Cooke (Steven_Cooke@carleton.ca), Fish Ecology and Conservation Physiology Laboratory, Institute of \\ Environmental Science and Department of Biology, Carleton University, Ottawa, ON, Canada K1S $5 B 6$
}

Scientific research is often thought of as two general categories: 1) basic (fundamental), curiosity-driven research where scientists seek to understand fundamental uncertainties, and 2) applied research undertaken to solve a specific problem. Most academic research falls under the former; however, some research programs are best described operating on a continuum between the two categories of scientific research. That is particularly the case in disciplines such as ecology and evolution, which have a history of theoretical and empirical fundamental research, as well as more recent applications of such knowledge for agriculture and conservation science. In these fields there are journals such as Ecology and Evolution on the basic end of the continuum, and Ecological Applications and Evolutionary Applications on the applied end.

I am not unlike other scientists in ecology and evolution. My research program is underpinned by the quest for knowledge and understanding of the fundamental basis of how animals function and interact with their environment. However, I am also part of a group of scientists who also seek to use such knowledge to understand and solve pressing conservation problems and inform environmental management and policy. As such, my research spans the entirety of the basic-applied continuum in the fields of ecology and the environment. At some level, this is a blessing. I am able to secure funds from a variety of sources including industry, NGOs, and government, provide students with skills that make them desirable to employers, and ideally, generate knowledge that has immediate application to environmental management and conservation science. But is that enough? Or, more appropriately, is that too much?
In academic circles, there is an ongoing conflict. For tenure and promotion, there seems to be an emphasis on basic science with little attention paid to the societal, economic, or environmental benefits of that work. All too often the merit of research is based on the type of journal where the work is published, or the number of times it is cited by peers. Alternatively, applied research has the potential to influence policy, lead to technological innovations, and be more palatable to and understood by the public and decision makers. A paper that could have a large and meaningful impact on conservation science, for example, would never have to be cited by another researcher to be influential. At present, there are few mechanisms to reward those that work on applied issues and, if anything, those who accept industry or government contracts risk being ostracized by colleagues who focus solely on fundamental research. Even in the disciplines of ecology and evolution, which have obvious connections to the environment and conservation, a Ph.D. thesis isn't good enough if it does not contribute to fundamental knowledge - applied projects are left to M.Sc. students. An applicant for the professoriate isn't good enough if they do not regularly publish in basic journals and have had many citations. These are outdated perspectives, though they remain pervasive in the scientific community, including in those individuals active in ecology and evolution. There are certainly exceptions (which tend to be natural resource, conservation science, or environmental science departments), but in many "traditional" departments of biology, ecology, evolution, botany, or zoology, this is the norm.

It is time for scientists, especially those in academia, to realize that we can and should devote more of our 
intellect and creativity to overcoming the many challenges that face society and the planet. We also owe it to future generations to ensure that those we train have the skills and the passion to work on complex real-world problems that require new ways of thinking about research and education (e.g., involving interdisciplinary approaches). Applied research demands collaboration and reaching across faculty barriers that all too often stifle interaction and interdisciplinary team-building (Sankar et al. 2007). Perhaps one reason why scientists have not fully engaged in addressing these challenges is the fact that they don't know how to collaborate (truly collaborative team work) due to a culture of focused and often solitary fundamental research endeavors. In practice, interdisciplinary research is by no means easy (Rhoten and Parker 2004), even though it is so sorely needed. Any and all efforts to encourage meaningful collaboration and interdisciplinary research should be encouraged.

Scientists continually emphasize the need to retain or expand funding for fundamental discovery-based science; however, taxpayers want research that provides socio-economic benefits. Indeed, some argue rather rationally that public funding should focus on "public" problems rather than fundamental curiosities. There is a growing expectation that science and technology can solve "grand challenges" (e.g., in environmental science [NRC 2001], earth system science [Reid et al. 2010], global health [Varmus et al. 2003], or organismal biology [Schwenk et al. 2009]) or help humanity in achieving millennium development goals (MDGs; see http://www.un.org/millenniumgoals/)-goals such as the eradication of extreme poverty and hunger, the attainment of environmental sustainability, and the reduction of child-mortality rates. There are also a growing number of exercises that have generated priority research questions that, if answered, would address long-standing scientific deficiencies in topics such as conservation science (e.g., Sutherland et al. 2009; Rudd et al. 2011). In 2006, the American Academy for the Advancement of Science (AAAS) annual meeting was themed around "grand challenges and great opportunities"; the president of AAAS noted that scientists were poised to tackle such problems and should seize these opportunities - if only we were asked to do so (Omenn 2006). For us, as individual researchers, to think that we have not been asked to do so implies a level of arrogance and disconnection with the real world that is virtually inconceivable. Indeed, there are many explicit examples of where science is needed to support the various initiatives described above. It is time to step up and do so.

I would submit that, today, there are still too few scientists in ecology and evolution that extend their work to the applied realm. Indeed, one could go so far as to argue that all possible minds and resources should be devoted to the lofty goals associated with the grand challenges and MDGs. So why are we not doing so-at least to a level that I personally find acceptable? It comes down to academic/scientific freedom and the need for the curiosity of individual researchers to dictate the focus of their scholarly pursuits. Many environmental and conservation questions are not first identified by scientists; policy makers and environmental managers identify knowledge gaps and management questions. Some, but not all, of these management questions can be modified into research questions that can be tackled by scientists. However, scientists must look for such opportunities or be open to them when they are presented. I am still new on the block as an academic, but my perspective is that scientists do not like being told where to focus their research effortsnor would I. On the same hand though, when an environmental manager contacts me and says "I need to know about $\mathrm{X}$ and want you to study it so I can make an informed decision about Y," I am utterly thrilled to have the possibility to be of direct "use" to the public good and the environment. Yet, there seems to be a fear that if we give leeway on the importance of fundamental research by acknowledging the value of applied research, let alone encourage it, then we will forever lose funding for fundamental research endeavors. I am in no way suggesting that fundamental research is unimportant or that funding for such programs should be reduced. In fact, the fundamental research of today provides the building blocks for future discoveries that could lead to innovations and socio-economic benefits. Still, I do suggest that there is ample room to more fully embrace applied research, particularly in ecology and evolution, and to tackle challenges that so desperately need science.

In ecology and evolution there are those that "do" applied research and those that "do not." Granting councils such as the Natural Sciences and Engineering Research Council (Canada) and the National Science Foundation (USA) continually evaluate their portfolios and the division of financial resources between fundamental and applied research. What I am suggesting is not an "either/or" scenario but, instead, that all researchers in ecology and evolution should consider working more broadly on the basic-applied continuum. In essence, I would like to see a paradigm shift-one that is a formal integration of the pursuit of new knowledge in ecology and evolution and the potential for and realization of its application to the public and environmental good. This is a subtle but important difference from what I regard as the status quo wherein the basic-applied continuum is somewhat linear. Perhaps we need to think about the basic-applied continuum as an integrated and dynamic feedback system rather than the typical dichotomy which is pervasive in science. There should not be any stigma 
associated with doing research that aims to benefit humanity and our planet. Indeed, we need mechanisms that both encourage and reward those that do, and that facilitate the interdisciplinarity and collaboration inherent in tackling complex applied problems. There have been calls to reorganize curricula around MDGs and/or grand challenges. And, nearly every strategic plan at research institutions around the globe pays lip service to themes consistent with environmental sustainability, food security, health, social justice, and so on. Why can't we, as individual scientists, also think more broadly about what we could do to yield tangible and measurable benefits?

We are in dire need of solution-based research for problems such as climate change, food security, water contamination, disease, and species declines. These problems cannot wait for fundamental research to yield solutions 50, 30 or even 10 years down the road. Although the MDGs are intended to be achieved by 2015, that target is lofty especially given that the MDGs have not been fully embraced by the scientists who have the potential to solve some of these problems. There is certainly no shortage of work or opportunity for scientists in ecology and evolution. At some level this is a plea to all scientists to consider how their knowledge and research programs could contribute to solving realworld problems. It is also a plea to think about how we can better train students to function along and appreciate the entirety of the basic-applied continuum, or even rethink how research can be done in a manner that does not differentiate between those two perspectives. Moreover, we as scientists need to better communicate results to policy-makers and the public. Success stories in the applied realm will not only benefit society and the natural world, they will also help justify the need for continued or even expanded support for all scientific endeavors across the entire basic-applied continuum. It is my desire that this commentary stimulates creative ideas on how better to realign our collective thinking about different types of science, and more importantly leads to concerted efforts to address the many challenges that face humanity and the natural world. I certainly do not have all of the answers, but I do know where there are questions that need to be answered, and encourage all researchers in ecology and evolution to consider how they can take the lead in doing so.

\section{Acknowledgements}

SJC is supported by the Canada Research Chairs Program, the Natural Sciences and Engineering Research Council of Canada, and the Ontario Ministry of
Research and Innovation. Caleb Hasler, Graham Raby, Nick Lapointe, and Lonnie Aarssen kindly provided input on earlier versions of this essay. I also wish to acknowledge my participation in a workshop on the science-policy interface organized by the Partnership Group for Science and Engineering in Canada that helped to shape some of my thinking.

\section{References}

National Research Council. 2001. Grand Challenges in Environmental Sciences: National Academy of Sciences, Washington, D.C., 106 pp. (September, 2009)

Omenn, G.S. 2006. Grand challenges and great opportunities in science, technology, and public policy. Science 314: 1696-1704. CrossRef

Reid, W.V., Chen, D., Goldfarb, L., Hackmann, H., Lee, Y.T., Mokhele, K. et al. 2010. Earth system science for global sustainability: grand challenges. Science 330: 916-917. CrossRef

Rhoten, D., and A. Parker. 2004. Risks and rewards of an interdisciplinary research path. Science 306: 2046. CrossRef

Rudd, M.A., Beazley, K.F., Cooke, S.J., Fleishman, E., Lane, D.E., Mascia, M.B. et al. 2011. Generation of priority research questions to inform conservation policy and management at a national level. Conservation Biology 25: 476-484. CrossRef

Sankar, P., Jones, N.L. and J. Karlawish. 2007. Evaluating existing and emerging connections among interdisciplinary researchers. BioScience 57: 965-972. CrossRef

Schwenk K., Padilla D.K., Bakken G.S., and R.J. Full. 2009. Grand challenges in organismal biology. Integrative and Comparative Biology 49: 7-14. CrossRef

Steele, T.W., and J.C. Stier. 2000. The impact of interdisciplinary research in the environmental sciences: a forestry case study. Journal of the American Society for Information Science 51: 476-484. CrossRef

Sutherland, W.J., Adams, W.M., Aronson, R.B., Aveling, R., Blackburn, T.M., Broad, S. et al. 2009. An assessment of the 100 questions of greatest importance to the conservation of global biological diversity. Conservation Biology 23: 557-567. CrossRef

Varmus, H., Klausner, R., Zerhouni, E., Acharya, T., Daar, A.S. and P.A. Singer. 2003. Grand challenges in global health. Science 302: 398. CrossRef 